\title{
CARACTERIZAÇÃO E IDENTIFICAÇÃO DE CULTIVARES E SELEÇÕES DE PEREIRAS ATRAVÉS DE MARCADORES RAPD ${ }^{1}$
}

\author{
HAIKO ENOK SAWAZAKI ${ }^{2}$, WILSON BARBOSA ${ }^{3,4}$, CARLOS AUGUSTO COLOMBO $^{2}$
}

\begin{abstract}
RESUMO - Trinta e seis acessos de pereira representando diversas espécies, híbridos e seleções do banco de germoplasma do Instituto Agronômico (IAC) foram geneticamente caracterizados através de marcadores RAPD. Cada primer originou de 10 a 19 bandas, sendo que 26 deles forneceram 250 bandas polimórficas, de um total de 353. Os primers OPC02, OPC08, OPD02, OPD19, OPD20 e OPE06 revelaram bandas específicas para as peras orientais e OPA01, OPA11, OPC08, OPD04, OPD09 e OPD15 para as ocidentais. O dendograma obtido foi confirmado pela análise de coordenada principal, originando três principais agrupamentos: 1) Todas as pereiras lançadas pelo IAC, como 'Seleta', 'Triunfo', 'Primorosa', 'Tenra', IAC 16-41, 'Centenária', além de 'William's', 'Packham's Triumph', 'D'água', 'Hood', 'M. Sieboldt', 'Kieffer', 'Branca Francesa' e 'Schimidt'. 2) As pereiras asiáticas, como 'Okusankichi', 'Shinseiki', 'Atago', 'Hakko', 'Hosui', 'Nijiseiki', 'Kosui' e 'Ya-li', além de 'Nodji', 'Limeira' e todas as seleções IAC das séries 193; 293 e 393. 3) Todas as pereiras porta-enxertos da série Taiwan ( P. calleryana D.), além de 'Manshu Mamenashi' (P. betulaefolia B.). Evidenciou-se que os cultivares IAC possuem maior proximidade genética com as peras ocidentais (Pyrus communis L.), mesmo sendo descendentes de 'Hood', material suspeito de ser híbrido interespecífico entre P. communis e P. serotina R.. Os resultados ratificaram a importância dos marcadores RAPD para a identificação de cultivares, seleções e híbridos pertencentes aos diferentes grupos botânicos, mostrando ser ferramenta de apoio adequada a programas de melhoramento genético de fruteiras.
\end{abstract}

Termos para indexação: Pyrus ssp, pereira, marcadores moleculares, RAPD, germoplasma, cultivares IAC, pêra oriental, pêra ocidental.

\section{GENETIC CHARACTERIZATION OF SELECTIONS AND PEAR CULTIVARS BY RAPD MARKERS}

ABSTRACT - In this research, 36 pear tree accessions represented by different species, hybrids, and cultivar selections were analyzed through RAPD. Each primer presented 10 to 19 bands, 26 primers have provided 250 polymorphic bands from a total of 353 . The OPC02, OPC08, OPD02, OPD19, OPD20 and OPE06 primers have identified specific bands for the oriental pears and OPA01, OPA11, OPC08, OPD04, OPD09 and OPD15, for the occidental pears. The obtained dendogram was confirmed by the principal coordinate analysis originating three principal groups: 1) All the pears originated by IAC, like 'Seleta', 'Triunfo', 'Primorosa', 'Tenra', IAC 16-41, 'Centenária', besides of 'William's', 'Packham's Triumph', 'D'água', 'Hood', 'M. Sieboldt', 'Kieffer', 'Branca Francesa' and 'Schimidt'. 2) The oriental pears, such as ' 'Okusankichi', 'Shinseiki', 'Atago', 'Hakko', 'Hosui', 'Nijiseki', 'Kosui' and 'Ya-li', besides 'Nodji', 'Limeira' and all the IAC selections from 193, 293 and 393 series. 3) All the rootstock from the Taiwan series (․ calleryana D.) and 'Manshu Mamenashi' ( $P$. betulaefolis B.). It became evident that IAC cultivars have higher genetic relationship with the occidental pears (Pyrus communis $L$.) than with the oriental pears. This fact is observed despite the fact that the IAC cultivars coming from 'Hood', material suspected to be an interspecific hybrid between $P$. communis $L$. and $P$. serotina $R$. These results confirm the importance the usefulness of the RAPD markers in identifying cultivars, selections, and hybrids belonging to different botanical groups, showing that RAPD markers are an important tool on the study of genetic diversity and genetic resource management of pears.

Index terms: Pear tree, Pyrus, molecular markers, RAPD, fingerprinting, germplasm, IAC cultivars, oriental pear, occidental pear.

\section{INTRODUÇÃO}

A pêra, pomácea pertencente ao gênero Pyrus, é a terceira fruta mais produzida no mundo depois da uva e maçã. O Brasil produz cerca de 20 mil toneladas anuais de peras das espécies Pyrus communis L. e P. serotina R., porém consome quase dez vezes mais, equivalente a $1,2 \mathrm{~kg}$.pessoa ${ }^{-1}$. Assim, o mercado brasileiro torna-se bastante dependente de importações, sendo a Argentina, Chile, Estados Unidos, Uruguai e Portugal os principais fornecedores (Oliveira et al., 2000). O gênero Pyrus, que conta com, pelo menos, 22 espécies, é originário de regiões montanhosas da China Ocidental (Vavilov, 1951), sendo que todas as espécies são nativas do continente asiático ou europeu (Rehder, 1967). A domesticação da espécie cultivada, P. communis L., provavelmente, deu-se ao leste da montanha do Cáucaso e Ásia Menor (Vavilov, 1951). Além das pereiras ocidentais $(P$. communis L.), amplamente cultivadas na Europa e América, também são fartamente encontrados os tipos asiáticos ou orientais (P. serotina R., P. ussuriensis R. e P. bretschneideri R.) na China e Japão (Kikuchi, 1946). Todas as espécies do gênero Pyrus são diplóides ( $2 n=34, x=17)$, preferencialmente alógamas, sendo que existem alguns casos de poliplóides na espécie $P$.

1 (Trabalho 019/2001). Recebido: 16/01/2001. Aceito para publicação: 04/06/2002. Pesquisa integrante dos subprojetos IAC: "Manutenção de germoplasma de fruteiras de clima temperado" e "Pereira: melhoramento genético". Apoio financeiro: PRONAF e Tesouro do Estado de São Paulo.

2 Eng ${ }^{\mathrm{a}}$ Agr $^{\mathrm{a}}$, Dra ${ }^{\mathrm{a}}$, Pesquisadora Científico (PqC), do Centro de Genética, Biologia Molecular e Fitoquímica, Instituto Agronômico (IAC), Caixa Postal 28, CEP 13001-970 Campinas, SP E-mail: henok@iac.br

3 Biólogo, M.Sc., PqC, Centro de Fruticultura, IAC. E-mail: wbarbosa@iac.br

4 Bolsista do CNPq. 
communis L. (Zielinski and Thompson, 1967).

Os programas de melhoramento de peras voltam-se principalmente para a qualidade do fruto, embora os atributos organolépticos possam diferenciar de um país para outro. Esse é o caso das pereiras européias em relação às asiáticas. Os atributos das peras européias, como casca lisa, aromáticas e tipo amanteigado, são menores no oriente, que prefere aquelas mais suculentas, adocicadas e ferruginosas. De modo geral, em ambos os casos, as cultivares com adequada adaptação e resistentes a pragas e doenças somente são aceitáveis se possuírem características desejáveis de fruto. Cruzamentos interespecíficos entre acessos das espécies asiáticas ou orientais, catalogadas no Brasil como Pyrus serotina Rehder, $P$. betulaefolia Bunge, $P$. calleryana Decaisne, $P$. bretschneideri Rehder, podem fornecer características fitotécnicas e organolépticas interessantes. Estas espécies têm, em sua grande maioria, características desejáveis, como fruto doce e crocante, além de rusticidade, ampla adaptação a variados tipos de clima e solo, alta produtividade e importante fonte genética de resistência a várias doenças e pragas que prejudicam as pereiras européias, da espécie $P$. communis L. No caso especifico do programa de melhoramento genético de pereiras do Instituto Agronômico (IAC), a obtenção de híbridos intra e interespecíficos, representados por pereiras asiáticas e européias, tem sido um dos objetivos, no sentido de se desenvolver cultivares com características agronômicas complementares, ou seja, rusticidade de planta e alta qualidade de frutos.

No entanto, dentro das espécies, os tipos são muito parecidos e, freqüentemente, a classificação é dificultada. Provavelmente, as espécies utilizadas podem ser confundidas com subespécies, variedades botânicas ou híbridos interespecíficos. Desta forma, muitos acessos existentes em bancos de germoplasma de pereira podem apresentar identidade genética desconhecida ou classificação botânica inadequada. Além disso, em muitos casos, as informações morfofenológicas disponíveis são insuficientes para discriminar genótipos aparentados.

Nos últimos anos, com o desenvolvimento da biotecnologia, diversas técnicas de marcadores moleculares têm permitido indicar com precisão as variações genética presentes no DNA de um organismo qualquer. Os marcadores moleculares mais utilizados atualmente, como SSR (single sequence repeat) ou polimorfismo de microssatélite (pequenas sequiências com um a quatro nucleotídeos de comprimento repetidas em tandem) e AFLP (amplified fragment lenght polymophism) ou polimorfismo de comprimento de fragmentos amplificados, requerem mais tecnologia para sua execução. Portanto, apesar da vantagem dos marcadores SSR de possibilitarem maior conteúdo de informação de polimorfismo, devido à expressão co-dominante e o multialelismo, em relação ao RAPD, que tem comportamento dominante, detectando apenas um alelo por loco, sua utilização é limitada pela necessidade prévia do desenvolvimento dos marcadores. Por sua vez, apesar de a análise AFLP possibilitar a obtenção de um grande número de marcadores em uma única análise, oriundos de análise multiplex e combinação do polimorfismo de presença e ausência de sítios de restrição com a ocorrência ou não de amplificação a partir de sequiências arbitrárias, têm comportamento dominante como o RAPD, detectando apenas um alelo por loco. Ainda, por ser uma análise mais sofisticada, demanda mais etapas para sua execução, sendo mais requerida em espécies de plantas cultivadas que apresentam uma baixa taxa de polimorfismo de DNA (Ferreira \& Grattapaglia, 1998). Já o RAPD (Random Amplified Polymorphic DNA) tem sido amplamente utilizado em pesquisas de genética de plantas, inclusive de pereiras, devido a sua facilidade de execução. Weeden et al. (1994), utilizando 70 primers de RAPD, encontraram cerca de 220 fragmentos polimórficos para a população segregante de um 'duplo pseudotestcross' em pêra. Oliveira et al. (1999), empregando a técnica RAPD para verificar o relacionamento entre vários cultivares de Pyrus communis, $P$. pyrifolia e genótipos de $P$. cordata, $P$. bourgaeana e $P$. pyraster, diferenciaram o padrão de pêra ocidental da oriental e encontraram marcadores específicos para alguns genótipos de cultivares. Monte-Corvo et al. (2000), também utilizando marcadores do tipo RAPD, foram capazes de discriminar genótipos de pêra do grupo oriental de ocidental, assim como dos seus híbridos. O uso de marcadores moleculares do tipo RAPD, associado às avaliações fenotípicas do material, pode ser útil em programa de melhoramento genético de pereira, para caracterização de acessos, bem como identificação rápida de seleções interespecíficas oriundas ou não de cruzamentos controlados. Esse é o caso do banco de germoplasma do Instituto Agronômico, que conta com cinco cultivares de pereiras lançadas pela Instituição e outras seleções IAC, oriundas de cruzamentos ou de polinização aberta, cuja origem e identificação genética ainda são incertas (Barbosa et al., 1997).

Neste trabalho, analisaram-se 36 acessos de pereira da coleção de trabalho do IAC, com a técnica RAPD, para se verificar a possibilidade de identificação e caracterização, além do relacionamento genético entre os acessos.

\section{MATERIAL E MÉTODOS}

O DNA das pereiras do Quadro 1 foi extraído de folhas jovens, utilizando-se do método com tampão de brometo de hexadeciltrimetilamônio (CTAB). Cerca de $0,5 \mathrm{~g}$ de tecido fresco foi triturado com $\mathrm{N}_{2}$ líquido e incubado a $65^{\circ} \mathrm{C}$ por 20 minutos com $5 \mathrm{ml}$ de tampão de extração (2\% CTAB; $1,4 \mathrm{M} \mathrm{NaCl} ; 20 \mathrm{mM}$ EDTA PH 8,0; 100mM Tris-HCl pH8, 0; 1\% PVP 40; $2 \%$ mercaptoetanol).

O extrato obtido foi submetido a uma extração com clorofórmio-álcool isoamílico (24:1), e centrifugada. O DNA na fase aquosa foi precipitado com $54 \%$ de volume de isopropanol e transferido para tubo eppendorff de $1,5 \mathrm{ml}$ para ser redissolvido com $200 \mu \mathrm{l} \mathrm{TE} \mathrm{pH} \mathrm{8,0} \mathrm{(10} \mathrm{mM} \mathrm{Tris-HCl} \mathrm{e} \mathrm{1mMEDTA).} \mathrm{A} \mathrm{mistura}$ foi, a seguir, digerida com RNase e extraída uma vez com fenolclorofórmio-álcool isoamílico e uma vez com clorofórmio-álcool isoamílico. O DNA foi precipitado com isopropanol, lavado com etanol 70\%, seco e dissolvido em TE pH 8,0 diluído10X. A quantificação e diluição do DNA foram medidas em fluorímetro e as reações de PCR realizadas no termociclador MJ PTC-100 com um volume de $10 \mu \mathrm{l}$. Foram utilizados cerca de $25 \mathrm{ng}$ de DNA em tampão de reação Tris- $\mathrm{HCl} 10 \mathrm{mM}$ pH 8,3 com 1,5mM MgCl2; $50 \mathrm{mM} \mathrm{KCl} ; 80 \mu \mathrm{M}$ de cada deoxinucleotídeo; $0,1 \% \mathrm{BSA} ; 0,1 \%$ NP-40 e 0,1 a $0,2 \mu 1$ de Taq DNA polimerase ( 5 unidades/ $\mu \mathrm{L}$ ). A amplificação foi iniciada a $94^{\circ} \mathrm{C}$, por 2 minutos, para a desnaturação inicial seguida por 45 ciclos de 15 segundos, a $94^{\circ} \mathrm{C}$

Rev. Bras. Frutic., Jaboticabal - SP, v. 24, n. 2, p. 447-452, agosto 2002 
QUADRO 1 - Trinta e seis cultivares e seleções de pereira dos tipos Oriental e Ocidental do BAG-IAC. Instituto Agronômico, 2000.

\begin{tabular}{|c|c|c|c|c|}
\hline $\mathbf{N}^{\mathbf{o}}$ & MATERIAL & ESPÉCIE & ORIENTAL & OCIDENTAL \\
\hline 1 & Schimidt (Smith) & Desconhecida & & $\mathrm{X}$ \\
\hline 2 & Manshu Mamenashi & Pyrus betulaefolia $B$. & $\mathrm{X}$ & \\
\hline 3 & IAC Primorosa & Desconhecida & & $\mathrm{X}$ \\
\hline 4 & IAC $16-41$ & Desconhecida & & $\mathrm{X}$ \\
\hline 5 & IAC Tenra & Desconhecida & & $\mathrm{X}$ \\
\hline 6 & Hood & Desconhecida & & $\mathrm{X}$ \\
\hline 7 & Kieffer & Desconhecida & $\mathrm{X}(?)$ & \\
\hline 8 & IAC Centenária & Desconhecida & & $\mathrm{X}$ \\
\hline 9 & Madame Sieboldt & Desconhecida & & $\mathrm{X}$ \\
\hline 10 & Nijiseiki & P. serotina $\mathrm{R}$. & $\mathrm{X}$ & \\
\hline 11 & IAC Triunfo & Desconhecida & & $X$ \\
\hline 12 & Taiwan Nashi-C & P. calleryana $\mathrm{D}$. & $\mathrm{X}$ & \\
\hline 13 & Taiwan Mamenashi & P. betulaefolia & $X$ & \\
\hline 14 & Taiwan Nashi-C (plântula 4) & P. calleryana $\mathrm{D}$. & $\mathrm{X}$ & \\
\hline 15 & Branca Francesa & Desconhecida & & $\mathrm{X}$ \\
\hline 16 & Packham's Triumph & P. communis $\mathrm{L}$. & & $\mathrm{X}$ \\
\hline 17 & Hakko & P. serotina $R$. & $\mathrm{X}$ & \\
\hline 18 & D’água & Desconhecida & & $X$ \\
\hline 19 & Okusankichi & P. serotina $R$. & $\mathrm{X}$ & \\
\hline 20 & Ya-li & P.bretschneideri $\mathrm{R}$. & $\mathrm{X}$ & \\
\hline 21 & Shinseiki & P.serotina $\mathrm{R}$. & $\mathrm{X}$ & \\
\hline 22 & Atago & P. serotina $\mathrm{R}$. & $\mathrm{X}$ & \\
\hline 23 & Nodji & Desconhecida & $\mathrm{X}(?)$ & \\
\hline 24 & Hosui & P. serotina $\mathrm{R}$. & $\mathrm{X}$ & \\
\hline 25 & William's & P. communis $\mathrm{L}$ & & $\mathrm{X}$ \\
\hline 26 & Kosui & P. serotina $\mathrm{R}$. & $\mathrm{X}$ & \\
\hline 27 & IAC $393-9$ & Desconhecida & $X$ & \\
\hline 28 & IAC $393-2$ & Desconhecida & $\mathrm{X}$ & \\
\hline 29 & Limeira & Desconhecida & $\mathrm{X}$ & \\
\hline 30 & IAC $293-29$ & Desconhecida & $\mathrm{X}$ & \\
\hline 31 & IAC $193-66$ & Desconhecida & $\mathrm{X}$ & \\
\hline 32 & IAC Seleta & Desconhecida & & $\mathrm{X}$ \\
\hline 33 & IAC $193-42$ & Desconhecida & $\mathrm{X}$ & \\
\hline 34 & IAC $193-62$ & Desconhecida & $\mathrm{X}$ & \\
\hline 35 & IAC $192-43$ & Desconhecida & $\mathrm{X}$ & \\
\hline 36 & IAC $293-23$ & Desconhecida & $\mathrm{X}$ & \\
\hline
\end{tabular}

(desnaturação), 25 segundos, a $34^{\circ} \mathrm{C}$ (anelamento) e 50 segundos, a $72^{\circ} \mathrm{C}$ (extensão), mais uma etapa para a completa extensão de todas as cadeias complementares de 5 minutos, a $72^{\circ} \mathrm{C}$. Foram utilizados os primers dos kits A, C, D e F da Operon Technologies para as reações de amplificação.

Os dados foram analisados pelo programa NTSYS, versão 1.70 (Rohlf, 1992), para a construção do dendograma e análise de coordenada principal, utilizando-se somente das bandas polimórficas mais consistentes em, pelo menos, duas amplificações para cada primer. O coeficiente de similaridade de Jaccard a/(n-d) foi estimado a partir dos dados de presença de banda (1) ou ausência (0), onde a = número de coincidências positivas (tipo 1-1), $\mathrm{n}=$ número total de amostras e d= número de coincidências negativas (tipo 0-0). A partir dos dados de coeficiente de similaridade gerados pelas bandas RAPD, foram feitas as análises dos agrupamentos, gerando o dendograma pelo método UPGMA e a análise de coordenada principal a partir do método de Gower (1966).

\section{RESULTADOS E DISCUSSÃO}

Vinte e seis primers forneceram polimorfismo, com um total de 250 bandas polimórficas, de um total de 353 (Tabela 1). Cada primer originou entre 10 a 19 bandas, sendo evidente o polimorfismo entre os acessos, como mostrado no exemplo de padrão de bandas RAPD obtido com o primer OPE11 (Figura 1). Somente com este primer verifica-se a existência da grande diversidade genética entre os acessos. Pode-se, também, ser vista a semelhança entre os híbridos IAC293-29 (30) e IAC293-23 (36) com a 'Okusankichi' (19), confirmando-a como um dos progenitores, assim como a maior similaridade com as peras orientais, pois o outro progenitor é a pêra 'D'água' (18) que, pelas análises, ficou como sendo do tipo ocidental. Da mesma forma, os híbridos 31 e 33 são mais semelhantes ao progenitor 'Atago' (22), de procedência oriental, do que a 'D'água', o outro progenitor, embora os outros híbridos, 34 e 35, aparentem ser, neste caso, mais próximos de 'D água' do que 'Atago'. A Tabela 
2 apresenta a relação dos primers que diferenciaram as peras com genótipo oriental das ocidentais. Os primers OPC02, OPC08, OPD02, OPD19, OPD20 e OPE06 revelaram bandas específicas para os cultivares orientais números $10 ; 17 ; 19 ; 20 ; 21 ; 22 ; 24 ; 26$; $27 ; 28 ; 29 ; 30 ; 31 ; 33 ; 34 ; 35$ e 36 , enquanto os primers OPA01, OPA11, OPC08, OPD04, OPD09 e OPD15 para os ocidentais 1; 3; $4 ; 5 ; 6 ; 8 ; 9 ; 15 ; 16 ; 18 ; 25$ e 32. A formação dos grupos, utilizandose do método de agrupamento UPGMA, originou o dendograma da Figura 2. O coeficiente cofonético computado da matrix da árvore mostrou correlação de 0,932 com a matrix de similaridade original, indicando boa correspondência dos agrupamentos aos dados. Verificou-se, pelo dendograma, três principais agrupamentos, ficando distintas as peras ocidentais das orientais e o grupo das Taiwan. No grupo ocidental, reuniram-se, além dos cultivares da espécie $P$. communis L., 'William's(25) e 'Packham's Triumph' (16), também, as seleções IAC ('P. Triumph' $x$ 'Hood'), como IAC 16-41 (4), 'Triunfo' (11), 'Centenária' (8), 'Primorosa' (3) e 'Seleta' (32), além de 'Tenra' (5) ('P. Triumph' $x$ 'Madame Sieboldt'). Com exceção de Seleta, os demais híbridos IAC formaram um grupo dentro do agrupamento das ocidentais, indicando também grande proximidade genética. 'Hood' e 'Madame Sieboldt' (9), cultivares receptoras e doadoras de pólen, respectivamente, estreitamente próximas, ficaram ligadas com a "Kieffer', dentro do grupo das ocidentais. Ressalte-se que 'Hood' (6) e 'Kieffer' (7) são citados na literatura como supostamente híbridos entre $P$. communis L. (ocidental) e P. serotina. R. (oriental) (Layne \& Quamme, 1975). Ainda dentro do agrupamento das ocidentais, foram relacionadas a D'Água (18), 'Branca Francesa' (15) e, mais distante, a 'Schimidt' (1). Dentro do agrupamento das pereiras asiáticas, ficaram bem definidos dois agrupamentos, sendo um composto pelos acessos da espécie $P$. serotina R., como 'Nijiseiki' (10), 'Hosui' (24), 'Hakko' (17), 'Okusankichi' (19), Shinseiki (21) e 'Atago' (22). A Shinseiki, suposto híbrido entre 'Nijiseiki' e 'Chojuro', foi confirmada próxima a 'Nijiseiki'. $\mathrm{O}$ único acesso da espécie $P$. serotina $\mathrm{R}$., que não foi relacionado neste agrupamento, foi 'Kosui' (26, oriundo do cruzamento entre 'Kikusui' e 'Wasekojo'), o qual ficou junto às seleções IAC oriundos de polinização livre da D’ Água (18): IAC 393-9 (27) e IAC 393-2(28), sugerindo possível ascendência destes híbridos. Ainda dentro do agrupamento dos híbridos entre D'Água e pereiras orientais, o grupo mais próximo, a seguir, foi o formado pelos híbridos IAC 293-29 (30) e IAC 293-23 (36), descendentes de 'Okusankichi' e o IAC 193-66 (31), de 'Atago'. O outro agrupamento próximo foi também formado a partir do cruzamento entre D'Água (18) e 'Atago' (22), constituindo os híbridos IAC 193-42 (33), IAC 192-62 (34) e IAC 192-43 (35). Isso é possível, pois sendo as pereiras 'D’Água' e 'Kosui', vizinhas próximas no lote experimental, podem ter sido interpolinizadas naturalmente. Ainda dentro do grupo das orientais, mais distantes, ficaram a 'Limeira' (29), Nodji' (23) e a 'Ya-li' (20, da espécie $P$. bretschneideri R.). Finalmente, o terceiro grupo distinto foi formado pelas pereiras porta-enxerto da série Taiwan (12 e 14, da espécie $P$. calleryana D. e 13 , da espécie $P$. betulaefolia B.) e um pouco mais distante, a 'Manshu Mamenashi' (2, da espécie $P$. betulaefolia B.). Embora 'Hood', como mencionado anteriormente, seja supostamente híbrido entre $P$. communis L. e $P$. serotina $R$, originou cultivares do cruzamento com a ' $P$. Triumph' que mostraram maior proximidade genética com as peras ocidentais (Pyrus communis L.), enquanto os híbridos originados entre acessos da P. serotina $\mathrm{R}$. com a 'D'Água' ficaram mais ligadas às orientais, evidenciando maior afinidade da 'Hood' com as pereiras ocidentais. Augustin et al. (1993) encontraram três padrões eletroforéticos da enzima isoperoxidase em acessos da $P$. calleryana $\mathrm{D}$., indicando que a heterogeneidade constatada nos porta-enxertos é, provavelmente, devido a variabilidade genética. A análise via RAPD confirma a diferença entre duas plantas desta espécie, a Taiwan Nashi-C (12) e Taiwan Nashi-C plântula 4 (14). Apenas com o primer OPE11 já se verificam diferenças entre as plantas, indicando, devido à facilidade da metodologia RAPD, ser este um método prático para se verificar a homogeneidade dos germoplasmas de pereira porta-enxerto. A dispersão gráfica dos dados, obtida pelo método de ordenação de coordenadas principais (Figura 3), originou os mesmos três principais agrupamentos obtidos pelo dendrograma. A primeira (PC1), a segunda (PC2) e a terceira (PC3) coordenadas principais foram responsáveis por $15,15 \% ; 9,64 \%$ e 5,04\% da variação total, respectivamente.

TABELA 1 - Lista dos primers polimórficos e do número de bandas observadas nos diversos acessos de pereira. Instituto Agronômico, 2000.

\begin{tabular}{|c|c|c|}
\hline Primer & $\begin{array}{c}\text { Número } \\
\text { total de bandas }\end{array}$ & $\begin{array}{c}\text { Número de } \\
\text { bandas polimórficas }\end{array}$ \\
\hline OP A - 01 & 12 & 7 \\
\hline O P A - 04 & 17 & 14 \\
\hline O P A - 07 & 19 & 16 \\
\hline O P A - 11 & 16 & 12 \\
\hline O P C -02 & 14 & 10 \\
\hline O P C -04 & 12 & 07 \\
\hline O P C - 07 & 15 & 12 \\
\hline $\mathrm{OPC}-08$ & 10 & 9 \\
\hline O P C -09 & 10 & 8 \\
\hline O P C - 10 & 10 & 7 \\
\hline O P C - 11 & 10 & 6 \\
\hline O P C -13 & 14 & 6 \\
\hline O P D - 01 & 14 & 10 \\
\hline O P D - 02 & 19 & 14 \\
\hline O P D - 04 & 14 & 10 \\
\hline O P D - 05 & 10 & 04 \\
\hline O P D - 06 & 12 & 05 \\
\hline O P D - 08 & 16 & 13 \\
\hline O P D - 09 & 15 & 12 \\
\hline O P D - 15 & 14 & 11 \\
\hline O P D - 19 & 15 & 12 \\
\hline O P D - 20 & 19 & 16 \\
\hline O P E - 06 & 14 & 09 \\
\hline O P E - 11 & 12 & 10 \\
\hline OPF-03 & 10 & 06 \\
\hline O P F - 20 & 10 & 04 \\
\hline
\end{tabular}

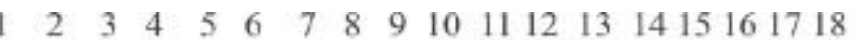

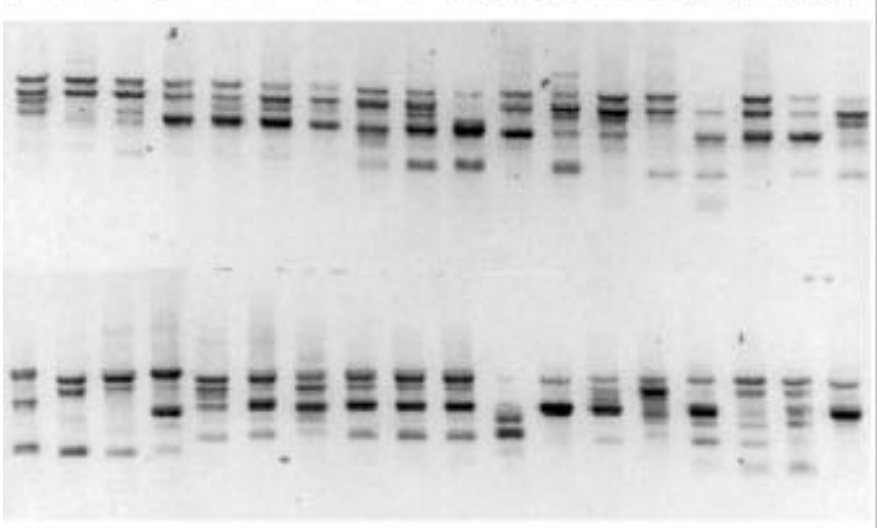

$19202122 \quad 2324252627282930 \quad 3132 \quad 33 \quad 343536$

FIGURA 1 - Perfil RAPD de 36 acessos de pereira obtido com o primer OPE11. A numeração corresponde aos acessos do Quadro 1. 
TABELA 2 - Primers de RAPD específicos para as peras com genótipo oriental ou ocidental (+indica a presença de banda).

\begin{tabular}{|c|c|c|c|c|c|c|c|c|c|c|c|c|}
\hline Primers & O P A 01 & O P A 11 & $\mathrm{OPC} 02$ & $\mathrm{OPC} 08$ & $\mathrm{OPC} 08$ & O P D 02 & O P D 04 & O P D 09 & O P D 15 & O P D 19 & O P D 20 & O P E 06 \\
\hline \multicolumn{13}{|c|}{ M aterial } \\
\hline $\begin{array}{l}1 \\
2\end{array}$ & + & & & + & & & + & + & + & & & \\
\hline 3 & + & + & & + & & & + & & + & & & \\
\hline 4 & + & + & & + & & & + & + & & & & \\
\hline 5 & + & & & + & & & + & + & & & & \\
\hline 6 & + & + & & + & & & + & + & + & & & \\
\hline 7 & + & & & + & & & & & & & & \\
\hline 8 & + & + & & + & & & + & + & + & & & \\
\hline 9 & + & + & & + & & & & + & + & & & \\
\hline 10 & & & + & & + & + & + & & & + & + & + \\
\hline 11 & & & & + & & & + & + & & & & \\
\hline 12 & & & & & & & & & & & & + \\
\hline 13 & & & & & + & + & & & & & & + \\
\hline 14 & & & & & & & & & & & & + \\
\hline 15 & + & + & & + & & & & & & & & \\
\hline 16 & + & & & & & & & + & + & & & \\
\hline 17 & & & + & & + & + & & & & + & + & + \\
\hline 18 & + & + & & & & & & + & + & & & \\
\hline 19 & & & + & & + & + & & & & + & + & + \\
\hline 20 & & & & & & + & & & & & + & + \\
\hline 21 & & & + & & + & & & & & + & + & \\
\hline 22 & & & & & + & + & & & & + & + & + \\
\hline 23 & & & & + & & & & & + & & & + \\
\hline 24 & & & + & & + & + & & & & + & + & + \\
\hline 25 & + & & & & & & & + & + & & & \\
\hline 26 & & & + & & + & + & & & & + & + & + \\
\hline 27 & & & & & + & + & & & & + & + & \\
\hline 28 & & & + & & + & + & & & & + & + & \\
\hline 29 & & & & & & + & & & & + & & \\
\hline 30 & & & & & & & & & & + & + & \\
\hline 31 & & & & & + & + & & & & + & + & + \\
\hline 32 & & + & & + & & & & + & + & & & \\
\hline 33 & & & + & & + & + & & & & + & + & \\
\hline 34 & & & + & & + & + & & & & + & + & + \\
\hline 35 & & & & & & + & & & & + & + & + \\
\hline 36 & & & + & & + & + & & & & + & + & + \\
\hline
\end{tabular}

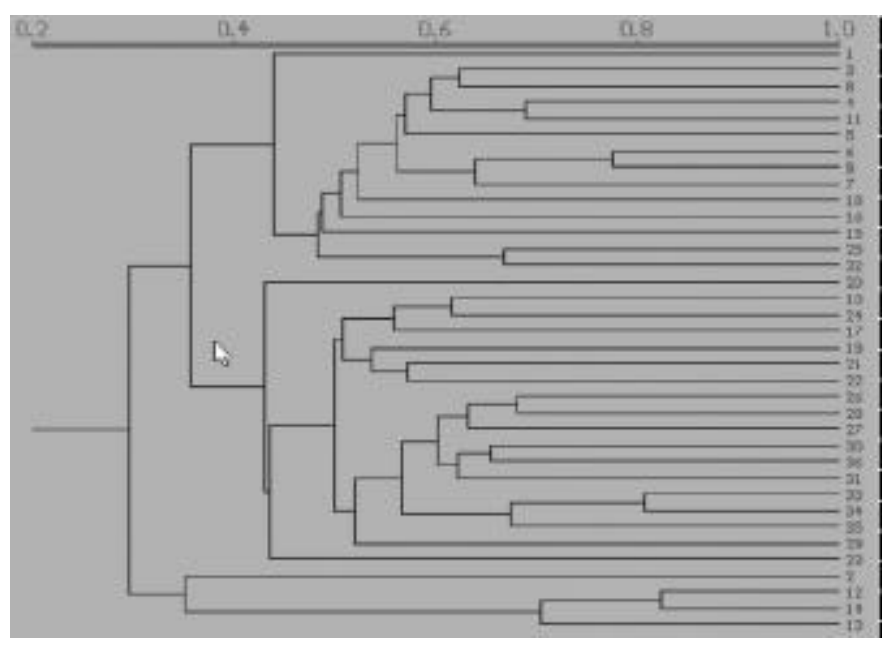

FIGURA 2 - Associações entre 36 acessos de pereira revelados pela análise de agrupamento UPGMA a partir do coeficiente de similaridade genética de Jaccard calculado de 250 bandas de RAPD geradas por 26 primers. A numeração corresponde aos acessos do Quadro 1.

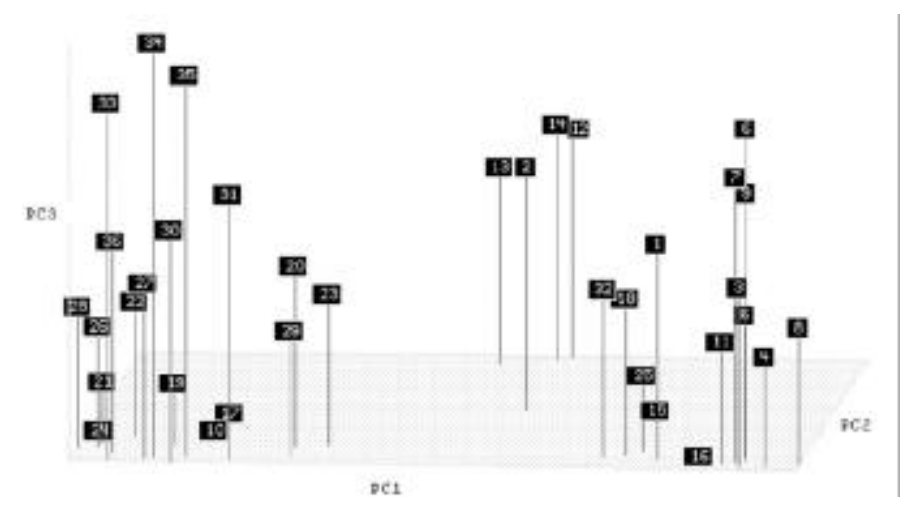

FIGURA 3 - Associações entre 36 acessos de pereira obtidos pela análise de coordenada principal dos coeficientes de similaridade de Jaccard calculados de 250 bandas RAPD geradas por 26 primers. A numeração corresponde aos acessos do Quadro 1. 


\section{CONCLUSÕES}

1. Verificou-se nítida separação entre os genótipos ocidentais e orientais e os das pereiras utilizadas como porta-enxertos.

2. A metodologia RAPD é prática para se identificar genótipo de pereira, podendo ser utilizada para verificar homogeneidade e facilitar a formação de mudas uniformes.

3. A caracterização das cultivares IAC permitiu identificar maior proximidade com a ascendência ocidental que oriental.

4. Para efeito de gestão de recursos genéticos de pereiras, os marcadores RAPD revelam-se importante ferramenta para identificação de duplicatas varietais.

5. Os marcadores RAPD podem auxiliar em muito os melhoristas da pereira, seja para identificação de prováveis parentais de híbridos, cuja origem é desconhecida, seja para estruturar a variabilidade genética no sentido de direcionar cruzamentos entre grupos heteróticos de interesse.

\section{AGRADECIMENTOS}

Os autores agradecem aos Técnicos de Apoio Marcilene de Moraes e Antonio Carlos de Carvalho os tratos culturais e a coleta de folhas das pereiras.

\section{REFERÊNCIAS BIBLIOGRÁFICAS}

AUGUSTIN, E.; NAKASU, B.H.; MACHADO C.A.E. Variabilidade das isoperoxidases em porta-enxertos de Pereira (Pyrus calleryana Done e P. betulaefolia Bunge). Pesquisa Agropecuária Brasileira, Brasília, v. 28 n.3, p. 329-331, 1993.

BARBOSA W.; CAMPO DALL'ORTO, F.A.; OJIMA, M.; CASTRO, J.L.; MARTINS, F.P.; MARTINS, A.L.M. Germoplasma e cultivo de pêra asiática no Estado de São Paulo. In: SIMPÓSIO LATINO-AMERICANO DE RECURSOS GENÉTICOS VEGETAIS, 1., 1997, Campinas. Resumos... p. 62

FERREIRA, M.E.; GRATTAPAGLIA, D. Introdução ao uso de marcadores moleculares em análise genética. EMBRAPACENARGEN, 1998. p.220.

GOWER, J.C. Some distance properties of latent root and vector methods used in multivariate analysis. Biometrika, London, v. 53, p. 325-338, 1966.

KIKUCHI, A. Speciation and taxonomy of Chinese pears. Collected Records of Hort. Res. n. 3, p. 1-8, 1946.

LAYNE, R.E.C.; QUAMME, H.A. Pears. In: JANICK, J.; MOORE, J.N. (Ed.) Advances in fruit breeding. West Lafayette: Pardue University, Press, 1975. p.38.

MONTE-CORVO L, CABRITA L, OLIVEIRA C, LEITAO. Assessment of genetic relationships among Pyrus species and cultivars using AFLP and RAPD markers. J. Genet. Res. Crop Evol. v. 47, p. 257-265, 2000.

OLIVEIRA, C.M; MOTA, M.; MONTE-CORVO, L.; GOULÃO, A.; SILVA, D.M. Molecular typing of Pyrus based on RAPD markers. Scientia Horticulturae, Amsterdam, v. 79, p. 163-174, 1999.

OLIVEIRA, E.L., BARBOSA, W.; MAIA, M.L. Análise dos mercados brasileiro e mundial de pêra. In: CONGRESSO BRASILEIRO DE FRUTICULTURA, 16., 2000, Fortaleza. Resumos... (cd room).

REHDER, A. Manual of cultivated trees and shrubs. $2^{\text {nd }}$ ed. New York: Macmillan, 1967.

ROHLF, F.J.; SLICE, D.E. NTSYS-pc Numerical Taxonomy and Multivariate Analysis System. NewYork: Exeter Publications, 1992.

VAVILOV, N.I. The origen, variation immunity and breeding of cultivated plants. New York: Ronald Press, 1951.

WEEDEN, N.F.; HEMMAT, M.; LAWSON, D.M.; LODHI, M.; BELL, R.L.; MANGANARIS, A.G.; REISCH, B.I.; BROWN, S.K.; G.-N.YE. 1994. Development and application of molecular marker linkage maps in woody fruit crops. Euphytica, Dochechat, 1994, v. 77 p. 71-75, 1994.

ZIELINSKY, Q.B.; THOMPSON M.M. Speciation in Pyrus: chromosome number and meiotic behaviour. Botanical Gazette, Chicago, v. 128, p. 109-112, 1967.

Rev. Bras. Frutic., Jaboticabal - SP, v. 24, n. 2, p. 447-452, agosto 2002 